\title{
The Impact of Basal Forebrain Lesions on the Ability of Rats to Perform a Sensory Discrimination Task Involving Barrel Cortex
}

\author{
S. Essie Jacobs' and Sharon L. Juliano',2 \\ 'Department of Anatomy and Cell Biology and ${ }^{2}$ Program of Neuroscience, Uniformed Services University of the Health \\ Sciences, Bethesda, Maryland 20814
}

Depletion of cortical acetylcholine (ACh) correlates with reduced stimulus-evoked 2-deoxyglucose (2-DG) uptake in rodent somatosensory cortex. We examined the effect of unilateral basal forebrain lesions and subsequent cortical ACh depletion on (1) the ability of rats to detect a passively applied deflection of the whiskers, and (2) whisker-evoked 2-DG uptake. Normal adult rats were trained on a T-maze to respond by turning in one direction if the whiskers were displaced and in the opposite direction on presentation of a sham stimulus; only the left set of whiskers was stimulated. When the animal performed at the $80 \%$ correct level for three consecutive sessions (criterion), it was randomly assigned to a group receiving either a saline injection (sham lesion) or an ibotenic acid injection (excitotoxic lesion) into the right basal forebrain. Behavioral testing continued until the animal returned to the prelesion criterion, at which time a terminal 2-DG experiment was conducted, None of the sham-lesioned rats experienced disruption of their ability to perform the task. All excitotoxic basal forebrain-lesioned rats were impaired in task performance, but eventually returned to prelesion performance levels. The length of time required to return to criterion was positively correlated with the amount of cortical ACh depletion. Despite the behavioral recovery of the ACh-depleted rats, 2-DG uptake in response to whisker stimulation continued to be reduced in the somatosensory cortex ipsilateral to the basal forebrain lesion. These findings suggest that ACh depletion, which results in a long-lasting decrease in neuronal responses to evoked stimuli, transiently impairs an animal's ability to perceive and appropriately respond to sensory information; the duration of impairment is related to the degree of depletion.

[Key words: $\mathrm{ACh}, \mathrm{AChE}$, cholinergic, cytochrome oxidase, 2-deoxyglucose, somatosensory cortex, vibrissa]

It is widely recognized that acetylcholine (ACh) is important in normal cortical processing (Krnjevic et al., 1971; Brown, 1983; McCormick and Prince, 1985; for review see McCormick, 1990). ACh appears to function as a neural modulator that enhances activity in response to stimulation. Combining iontophoretic

\footnotetext{
Received Dec. 27, 1993; revised July 15, 1994; accepted July 25, 1994.

This work was supported by R07064 (S.L.J.). We are grateful to Dr. James E. Barrett for advice on the behavioral procedure, and to Dr. Marina Volkov for assistance on statistical methods. This work is submitted in partial fulfillment for the degree of Doctor of Philosophy to S.E.J.

Correspondence should be addressed to Dr. Sharon L. Juliano, Department of Anatomy and Cell Biology, Uniformed Services University of the Health Sciences, 4301 Jones Bridge Road, Bethesda, MD 20814.

Copyright (C) 1995 Society for Neuroscience $0270-6474 / 95 / 151099-11 \$ 05.00 / 0$
}

application of $\mathrm{ACh}$ with appropriate sensory stimuli enhances neuronal responsiveness in the somatosensory cortex (Donoghue and Carroll, 1987; Metherate et al., 1987, 1988a,b; Lamour et al., 1988), visual cortex (Sillito and Kemp, 1983; Sato et al., 1987), and auditory cortex (McKenna et al., 1988; Metherate and Weinberger, 1989, 1990). On the other hand, few cortical neurons respond to iontophoresis of $\mathrm{ACh}$ alone. $\mathrm{ACh}$ is also an important factor in mediating cortical plasticity in young and adult animals, since, in both visual and somatosensory cortex, rearrangements of neocortical function that occur following peripheral manipulation are prevented in the absence of cortical ACh (Bear and Singer, 1986; Juliano et al., 1991; Webster et al., 1991).

Alzheimer's disease is characterized by marked loss of cholinergic cells in the basal forebrain and loss of ACh in the cerebral cortex (Whitehouse et al., 1981, 1982; Price et al., 1982; Candy et al., 1983). Clinical studies with such patients routinely relate the cholinergic deficits to memory decline (for reviews, see Bartus et al., 1982; Coyle et al., 1983; Collerton, 1986). Several studies, however, demonstrate pronounced deficits in both tactile and visual discrimination in individuals with Alzheimer's disease compared to those with Parkinson's disease (Nissen et al., 1985; Freedman and Oscar-Berman, 1987), suggesting that the neuropathology of Alzheimer's disease may result in a reduced ability to detect sensory stimuli.

Previous experiments by this laboratory indicate that unilateral ACh depletion leads to reduced 2-deoxyglucose (2-DG) uptake in response to somatic stimulation (Ma et al., 1989; Juliano et al., 1990; Jacobs et al., 1991). This effect is mimicked by topical application of a cholinergic antagonist (Juliano et al., 1990). In addition, background levels of activity in surrounding "unstimulated" regions of cortex that are ACh-depleted remain of normal intensity (Ma et al., 1989), suggesting the reduction in 2-DG uptake is stimulus related.

Although a number of earlier studies investigated the effect of basal forebrain lesions on behavior, they have not clearly distinguished the ability to perform sensory discriminations from the ability to learn. For example, several studies used sensory discrimination paradigms to assess task acquisition, postlesion retention of a previously learned task, or rate of correct responding following the imposition of a time delay between stimulus presentation and response choice (Ridley et al., 1985, 1986; Irle and Markowitsch, 1987; Wozniak et al., 1989b). Although these and other experiments suggest a relationship between $\mathrm{ACh}$ and sensory behavior, very few studies have specifically investigated sensory discrimination performance after $\mathrm{ACh}$ depletion. The study presented here tests the ability of rats to perceive and respond to a tactile stimulus delivered to mystacial whiskers 


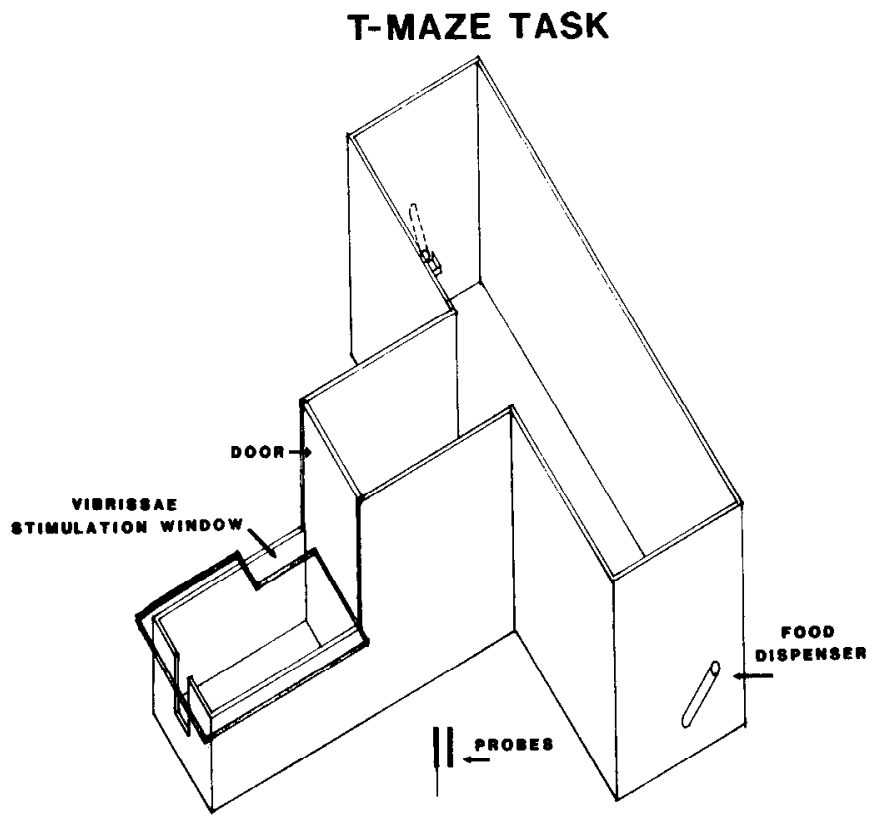

Figure 1. Illustrated is the T-maze apparatus used for the whisker sensory discrimination task. A rat placed in the start box received a whisker deflection using the long probe, or a sham deflection using the short probe. The door then opened and the rat obtained a food pellet reward for turning right when the whiskers were deflected, or for turning left when the whiskers were not deflected.

before and after ACh depletion. The performance of the rats was correlated with 2-DG uptake in the barrel field.

\section{Materials and Methods}

\section{Experimental design}

Rats were trained to respond to stimulation of the whiskers. When each rat reached a preset level of performance, it was randomly assigned to receive either a saline injection or an ibotenic acid injection into the right hemisphere of the regions of the basal forebrain that provide the major source of $\mathrm{ACh}$ to the cerebral corlex, particularly the nucleus basalis magnocellularis (nbm) (Johnston et al., 1979; Mesulam et al., 1983; Saper, 1984). Postlesion behavioral testing continued until the animal returned to prelesion criterion, at which time a 2-DG experiment was conducted.

\section{Subjects}

A total of 13 female Sprague-Dawley rats, weighing 175-200 gm, were used in this study. The rats were individually housed and maintained on a 12:12 hr light:dark cycle. Water was provided ad libitum; food was weighed and offered once daily to maintain the rats at $85 \%$ of their freefeeding weight. Weights were obtained from each rat once a week to ensure maintenance.

\section{Apparatus}

A wooden T-maze painted black with polyurethane coating was used for the behavioral task (Fig. 1). As previously described by Hurwitz et al. (1990), a start chamber, separated from the rest of the apparatus by a guillotine door, was covered by a clear Plexiglas lid with an opening adjacent to the door. Stimuli were presented through the opening to the left set of whiskers of each rat. The end of each goal arm contained a food cup into which Noyes dustless pellets $(45 \mathrm{mg})$ were manually dispensed. Throughout the training and testing, the room was illuminated by a red safety light, which hung $80 \mathrm{~cm}$ above the floor of the T-maze, oriented in a manner to provide only indirect light. $A$ handheld probe of insulated wire ( 20 gauge) was used to manually stimulate the whiskers (Fig. 1).

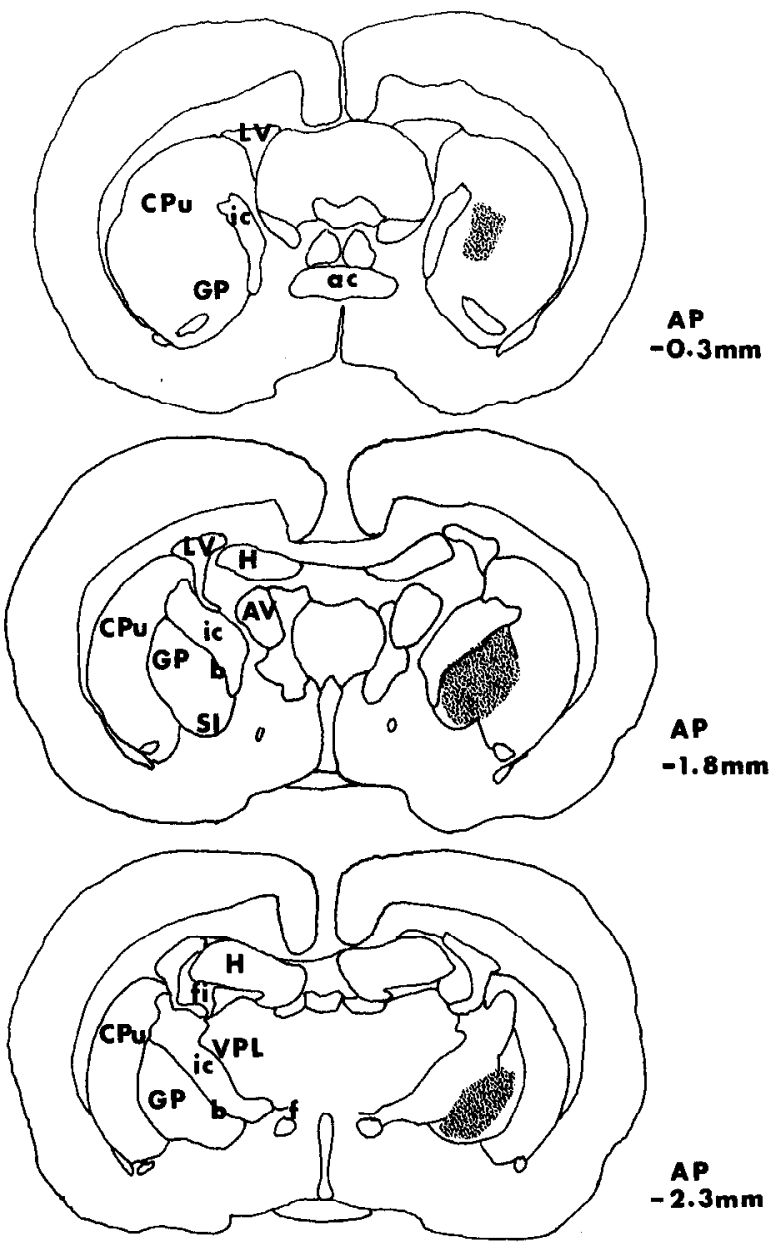

Figure 2. Reconstruction of a typical basal forebrain lesion. Drawing to indicate placement of the lesion viewed in the coronal plane. Regions affected by injections of ibotenic acid (shading) include the nucleus basalis magnocellularis $(b)$, the substantia innominata $(S I)$, and the ventromedial globus pallidus $(G P)$. The anteroposterior $(A P)$ levels of the representative sections are taken from Paxinos and Watson (1982). $a c$, anterior commissure; $A V$, anteroventral nucleus of the thalamus; $C P u$, caudate putamen; $f$, fornix; $f$, fimbria; $H$, hippocampus; $i c$, internal capsule; $L V$, lateral ventricle; $V P L$, ventroposterolateral nucleus of the thalamus.

\section{Behavioral procedure.}

Shaping. During the shaping phase, a rat was initially guided to the food bins by baiting the path with pellets. Once the animal ate from the bins, food was no longer placed on the floor and the shaping phase was replaced by a training phase.

Training. Prior to the lesion procedure, rats were trained to respond appropriately to whisker stimulation. The rat was placed in the start box facing the guillotine door and the Plexiglas lid put in place to cover the space. With the rat in this position, a stimulus was presented through the lid opening that consisted of either (1) a brisk caudal-to-rostral deflection of the whiskers along the left side of the face using a probe $15 \mathrm{~cm}$ long, or (2) a sham stimulus using a $10 \mathrm{~cm}$ long probe that provided all the stimulus cues but in which no whisker contact was made (Fig. 1). Attempts were made to eliminate visual cues, since the sessions were conducted using a dim, red light and the probe was made of a thin, dark wire making it difficult to detect visually. In addition, the stimuli were delivered from a caudal to rostral direction, while the rat directed its gaze forward, away from the probe. Immediately after administration of the stimulus, the door was opened to the main alley. The rat received a food pellet reward for turning right if its whiskers were deflected, and for turning left if the whiskers were not deflected. Determination of the goal arm was, therefore, dependent on the ability of the rat to discriminate whether or not its left-side set of whiskers 

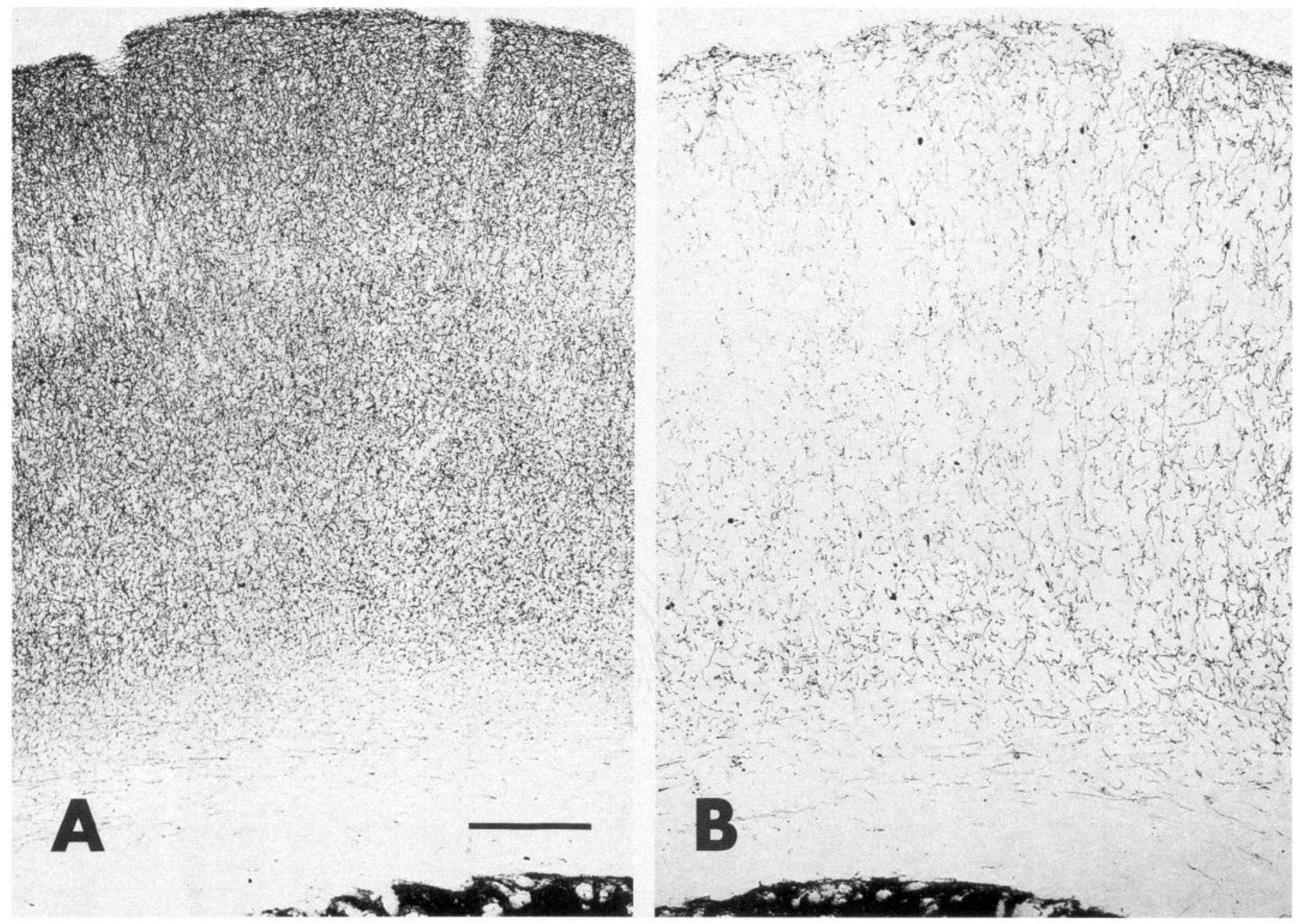

Figure 3. Photomicrograph of AChE fiber staining taken through the somatosensory cortex of both hemispheres of an animal that received a basal forebrain lesion. The hemisphere ipsilateral to a basal forebrain lesion $(B)$ displays greatly reduced AChE reactivity compared to the normal $(A)$ hemisphere. The amount of AChE depletion was quantified using our image analysis system, and the staining in $B$ reflects $56.9 \%$ of the staining in $A$. Scale $=250 \mu \mathrm{m}$.

were displaced. The rats received training $6 \mathrm{~d}$ a week during which time problem behaviors (e.g., side preferences, aversive reaction to handling) were extinguished. When a rat performed at better than chance level on three occasions, the training phase ended and a formal testing phase began.

Testing. Testing was conducted three times a week, with each test session consisting of 80 trials divided equally into 40 whisker deflections and 40 sham deflections. Selection of the stimulus (actual deflection vs. sham deflection) was randomly determined with the restriction that no more than three consecutive trials be the same. The criterion established prior to the lesion was performance of three consecutive sessions at the $80 \%$ correct level. Within $48 \mathrm{hr}$ after achieving this criterion, the animal was prepared for surgery.

\section{Surgery}

Basal forebrain lesion. Animals were randomly assigned to a group receiving either an excitotoxic lesion of the basal forebrain $(N=8)$ or a sham lesion $(N=5)$. Each animal was anesthetized with $7 \%$ chloral hydrate i.p. $(40 \mathrm{mg} / 100 \mathrm{gm})$, placed in a stereotaxic apparatus, and prepared for surgery. A small opening was made in the skull $4.0 \mathrm{~mm}$ anterior to bregma and $2.3 \mathrm{~mm}$ lateral from midline. A Hamilton syringe containing $1 \mathrm{ml}$ of either sterile saline (sham lesion) or the excitatory amino acid, ibotenic acid, $(10 \mu \mathrm{g} / \mu \mathrm{l})$ (excitotoxic lesion) was angled $36^{\circ}$ from vertical, $12^{\circ}$ lateral, and advanced $8 \mathrm{~mm}$ from the dura. These coordinates were previously established as an effective way to approach the area of the basal forebrain without traversing the somatosensory cortex (Jacobs et al., 1991). Forty-eight hours after surgery, the postle- sion behavioral phase of the experiment began. During these sessions, the examiner was blind to which rat was performing at any given time. The rat participated in testing three times/week until its performance again reached the prelesion criterion. At this point a terminal 2-DG experiment was administered.

2-DG procedure. Each rat was anesthetized with halothane (1.5\%) and a catheter placed in the jugular vein. A local anesthetic was applied to the skin around the catheter, and the rat loosely restrained on a block. All whiskers were trimmed bilaterally except for $\mathrm{C} 3$ or $\mathrm{C} 2$. The halothane was discontinued and the animal allowed to recover from the effects of the anesthetic for 1.5-2 hr. At this time, using hand-held brushes, manual stimulation of the remaining matched pair of whiskers began. Five minutes after the onset of stimulation, a pulse injection of 2-DG (2-deoxy-D-[1-14 C]glucose, $10 \mu \mathrm{Ci} / 100 \mathrm{gm})$ was administered intravenously and the stimulation continued for $45 \mathrm{~min}$, at which time sodium pentobarbital $(50 \mathrm{mg} / \mathrm{kg})$ was injected intravenously and the animal transcardially perfused with saline, followed by $0.1 \mathrm{M}$ phosphatebuffered paraformaldehyde ( $4 \%$ ) with $4 \%$ sucrose. The brain was quickly removed, frozen in Freon 22, and stored in a freezer at $-70^{\circ} \mathrm{C}$.

\section{Tissue processing}

Brains were cut in a cryostat at $-16^{\circ} \mathrm{C}$ at a thickness of $30 \mu \mathrm{m}$. Alternate sections were saved for 2-DG autoradiography, acetylcholinesterase (AChE) histochemistry (Koelle, 1955; Jacobowitz and Creed, 1983), and cytochrome oxidase (CO) histochemistry (Wong-Riley, 1979). Sections saved for 2-DG autoradiography were picked up on $2 \%$ gelatin- 


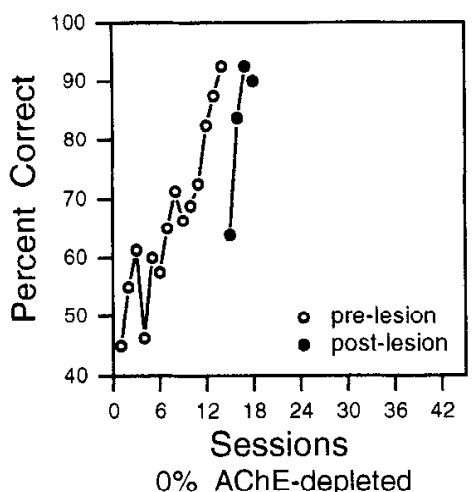

$0 \%$ AChE-depleted

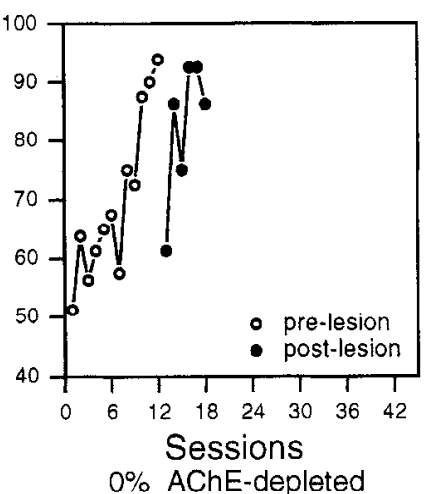

$0 \%$ AChE-depleted

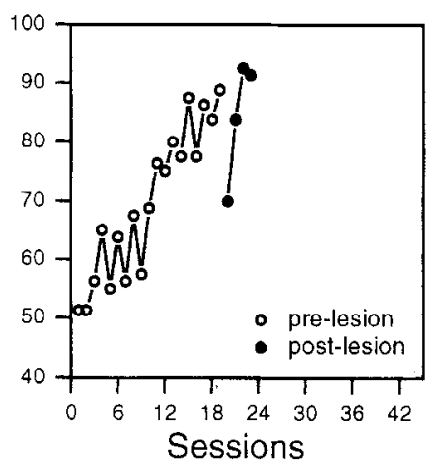

$2.0 \%$ AChE-depleted
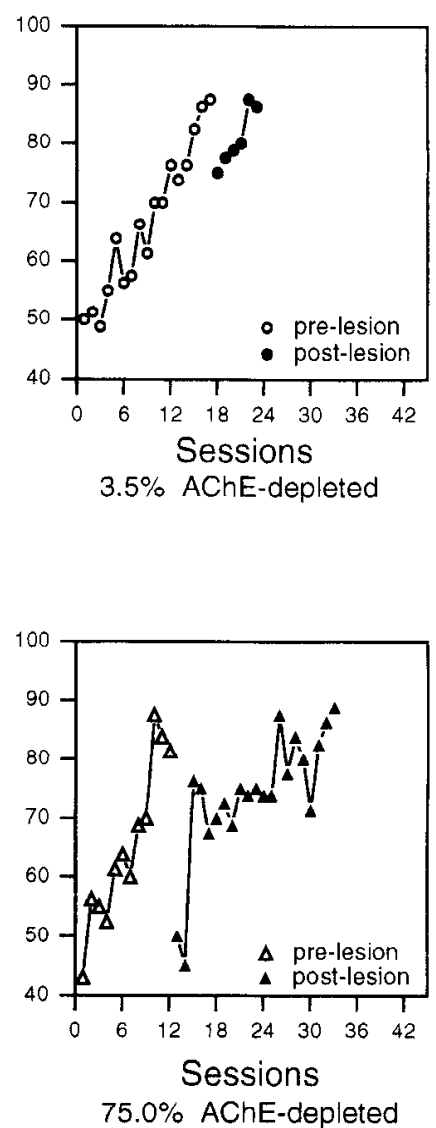
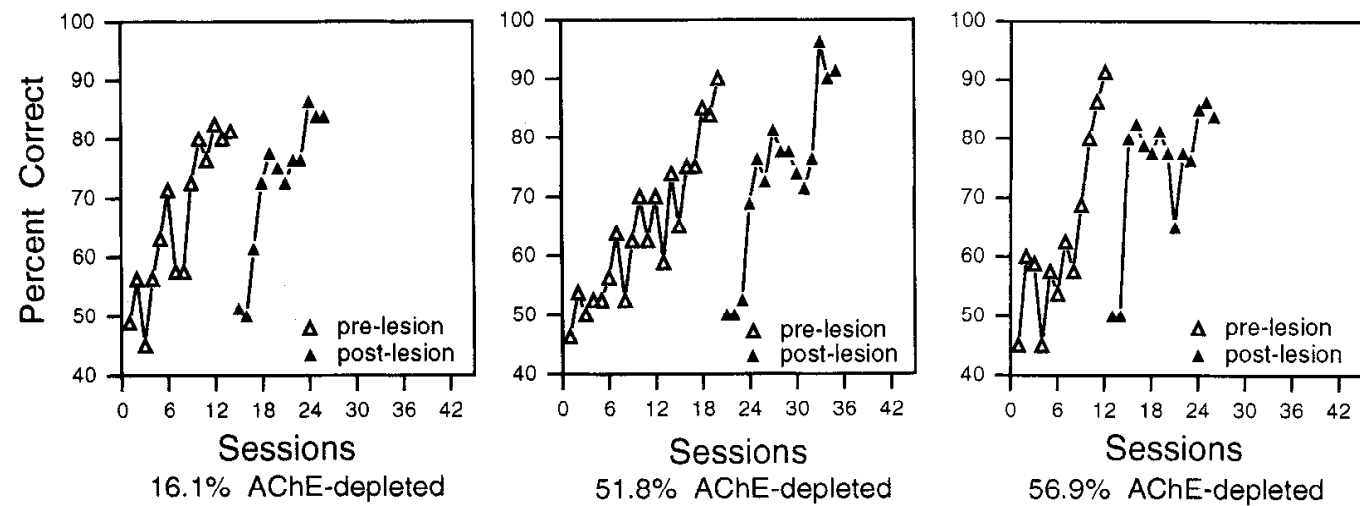

Figure 4. Learning curves for four sham-lesioned rats (top row; circles) and four rats that received excitotoxic lesions of the basal forebrain (bottom row; triangles). Prelesion testing sessions, indicated by open symbols, concluded when the animal performed at the $80 \%$ level for three consecutive performances (criterion). Closed symbols indicate testing sessions conducted following the lesion procedure until criterion was again achieved; animals tested three times a week. The amount of cortical AChE depletion, expressed as a percentage of staining in the opposite normal hemisphere, is indicated below each profile. All sham-lesioned rats returned to criterion within l week. Excitotoxic-lesioned animals required variable lengths of time (3-8 weeks) to return to prelesion performance levels.

coated slides and placed on a warming tray at $60^{\circ} \mathrm{C}$ for rapid dehydration. To prepare the 2-DG autoradiographs, the slides were placed in an $\mathrm{x}$-ray cassette along with ${ }^{14} \mathrm{C}$ methylacrylate standards and exposed to $\mathrm{x}$-ray film (SB-5, Kodak) for $7 \mathrm{~d}$.

\section{Data analysis}

Quantification of cortical ACh depletion. Three brains were evaluated by counting AChE-stained fibers according to the method described by Stichel and Singer (1987); optical density measurements of cortical AChE staining were also conducted using a video-based image analysis system with a PDP 11/23+ computer and custom-designed software. A linear relationship was found between the number of fibers and the optical density measurements. By expressing the mean optical density of AChE staining in the experimental hemisphere as a percentage of the normal hemisphere, the amount of cortical AChE depletion in the lesioned hemisphere was determined for each animal. Cortical regions specifically evaluated for AChE density included the regions containing the activated barrels in both hemispheres, as identified by adjacent autoradiographic and $\mathrm{CO}$-stained sections, and a region of cortex within the barrel field that was not specifically activated. Although AChE histochemistry does not directly measure ACh content, a number of studies recognize this technique as an accurate method for assessing ACh depletion (Höhmann et al., 1988; Ma et al., 1989).

2-DG autoradiographic analysis. Optical density values in the individual autoradiographic sections containing barrel-associated regions of increased activity were measured in specified matched sites in control and experimental hemispheres: (1) the activated barrel, (2) a region of cortex surrounding the activated barrel but not specifically stimulated, and (3) the underlying white matter (which represented background activity). By expressing the optical density values in the activated barrel and in the surrounding cortex as a percentage above background, differences in 2-DG activity were determined between hemispheres.

Digitized maps of metabolic activity in the somatosensory cortex were generated from autoradiographic sections every $100 \mu \mathrm{m}$ in the coronal plane. The autoradiographs wcrc displayed and details of the 2-DG label enhanced using look-up tables that transform the ${ }^{14} \mathrm{C}$ values to gray scales. The cortical area of interest was designated by drawing a line through layer IV of the selected region using a digitizing tablet and custom-designed software. The indicated region was partitioned into vertical and laminar arrays of high resolution; vertical bins, approximately $50 \mu \mathrm{m}$ wide and spanning layers II-V were generated. The average density value throughout a given bin (i.e., layers II-V) was obtained and collapsed to a single point. By aligning and displaying all bin files containing the density information, digitized maps of metabolic activity in the flattened somatosensory cortex were generated that allowed us to visualize the average density throughout layers II-V (Tommerdahl et al., 1985). Both sides of the brain on a single section were digitized and analyzed simultaneously to ensure identical treatment of the two hemispheres.

Spots of increased 2-DG uptake corresponding to the barrels activated by whisker stimulation during the 2-DG procedure were evident in the two-dimensional maps. The area of increased activity was determined by obtaining the average pixel intensity for the entire cortical map of each hemisphere, and displaying only those regions that corresponded to pixel values at least $1.5 \mathrm{SD}$ above the average intensity. The areas of the high intensity foci were measured using a digitizing tablet. These measurements allowed comparison of the areas of the barrel-associated spots between hemispheres.

Statistics. Descriptive statistics, analysis of variance (ANOVA), and correlation coefficients were computed using SYSTAT 5.0 for Windows (SYSTAT, Inc.). Statistical comparisons between group (sham- vs. ex- 
Number of Sessions to Return to Pre-Lesion Criteria

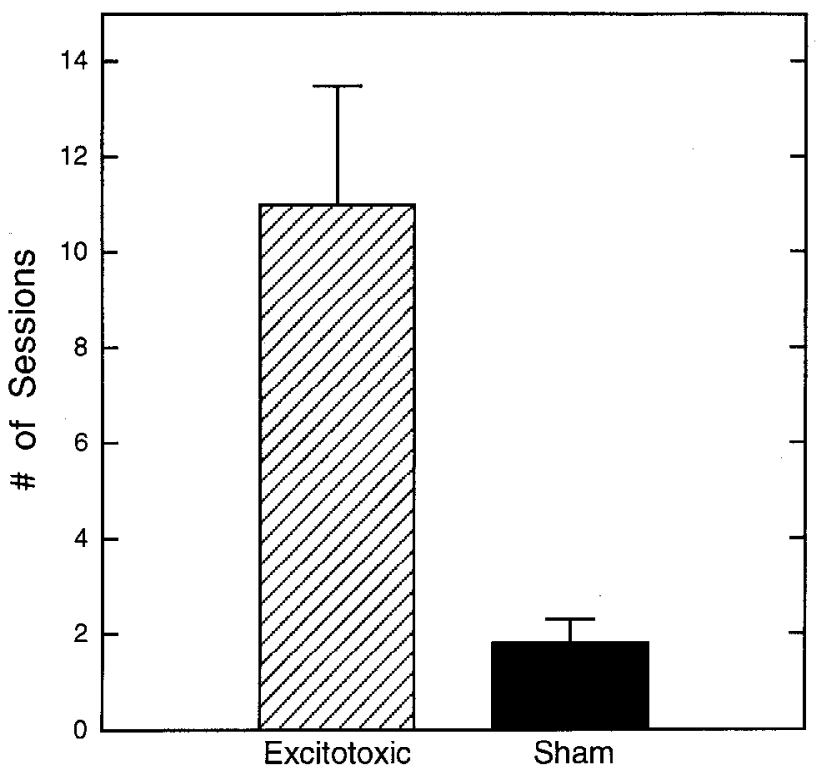

Figure 5. The number of postlesion testing sessions required by rats in the sham-lesioned group (black bar) was significantly different from the number of sessions required by the excitotoxic-lesioned rats (striped bar) $(p<0.015)$. The mean number of postlesion sessions for the shamlesioned animals was $1.8(\mathrm{SEM}=0.049)$, while for the excitotoxiclesioned animals the mean was $11.0(\mathrm{SEM}=2.478)$.

citotoxic-lesioned) and sessions to reach criterion, and between group and areal dimension of 2 -DG label were conducted using a $2 \times 2$ ANOVA.

\section{Results}

\section{Analysis of the lesion and AChE depletion}

Each lesion was carefully analyzed for placement. A successful lesion was confined to the $\mathrm{nbm}$ and the ventromedial globus pallidus, and did not encroach on the thalamus (Fig. 2). $\mathrm{CO}$ histochemistry was used to define the lesion borders, along with Nissl and AChE staining (Ma et al., 1989; Juliano et al., 1990). The intensity of $A C h E$ staining was reduced in the frontoparietal cortex ipsilateral to the excitotoxic lesion throughout all cortical layers. The amount of $\mathrm{AChE}$ depletion ranged from 16-75\% below the intensity of the unlesioned hemispheres. An example of cortical $\Lambda \mathrm{ChE}$ depletion is demonstrated in Figure 3, and reflects a decrease of $56.9 \%$ in AChE-stained fibers. Sham lesions did not lead to significant differences in AChE staining density between "experimental" and control hemispheres; the difference in density of AChE innervation between hemispheres of the control animals (i.e., sham-lesioned) ranged from $0-3.5 \%$. The amount of depletion was also correlated with the performance of each rat in the maze task (see below).

\section{Maze performance}

All sham-lesioned rats returned to their prelesion performance levels within the first week postlesion (1-3 sessions). Figure 4 shows learning curves for four sham- and four excitotoxic-lesioned rats. Also indicated in Figure 4 is the amount of $\mathrm{AChE}$ depletion in the right hemisphere of each rat. Comparison between the number of sessions required to return to prelesion criterion for the sham-lesioned rats versus the excitotoxic-lesioned rats was significantly different (Fig. 5). Animals that re-

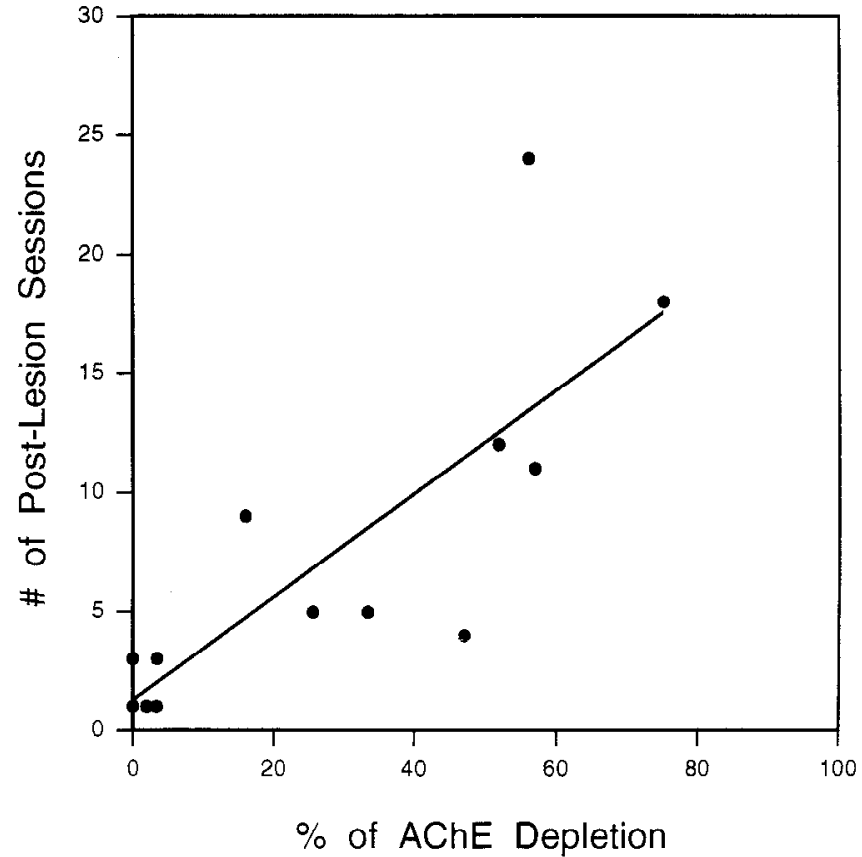

Figure 6. The relationship between the amount of cortical AChE depletion and the number of postlesion sessions to criterion is plotted. A strong correlation can be seen $(p<0.002)$.

ceived excitotoxic lesions required variable periods of postlesion testing before reaching prclcsion criterion, ranging from 4-24 sessions. Those with less effective excitotoxic basal forebrain lesions (i.e., $16-47 \%$ depleted) returned to criterion within 2-3 weeks, while rats with substantial ACh depletion (51-75\%) required 3-8 weeks to demonstrate restored performance ability. There was a strong correlation between the amount of AChE depletion and the number of sessions required to return to prelesion criterion $(r=0.81, p<0.002)$ (Fig. 6).

\section{2-DG uptake}

Metabolic activity evoked by single-whisker stimulation was evaluated in the individual autoradiographs and in digitized two-dimensional maps of 2-DG uptake. Column-like distributions of label were found in the individual autoradiographs in regions corresponding to the stimulated barrels. Within the site of high 2-DG density and the surrounding cortical regions, no significant differences in mean density of 2-DG uptake occurred between the normal and lesioned hemispheres. This held for both excitotoxic- and sham-lesioned animals. The foci of 2-DG label evoked by whisker stimulation were decreased in dimension in the ACh-depleted hemispheres of the excitotoxiclesioned rats compared to the label in the corresponding opposite hemispheres (Fig. 7). In sham-lesioned animals, no diffcrences in the size of metabolic uptake pattern were observed between hemispheres.

Two-dimensional maps of activity were constructed for seven of the animals undergoing behavioral testing. Since the maps provide a tangential view of barrel cortex, spots of label that corresponded to a barrel-associated column were visualized so that each whisker stimulated led to a focus of label. The area of increased metabolic activity, at least 1.5 SD above background, was measured in both hemispheres. In each ACh-depleted hemisphere, the area of uptake was reduced in comparison to the matched counterpart in the opposite hemisphere 

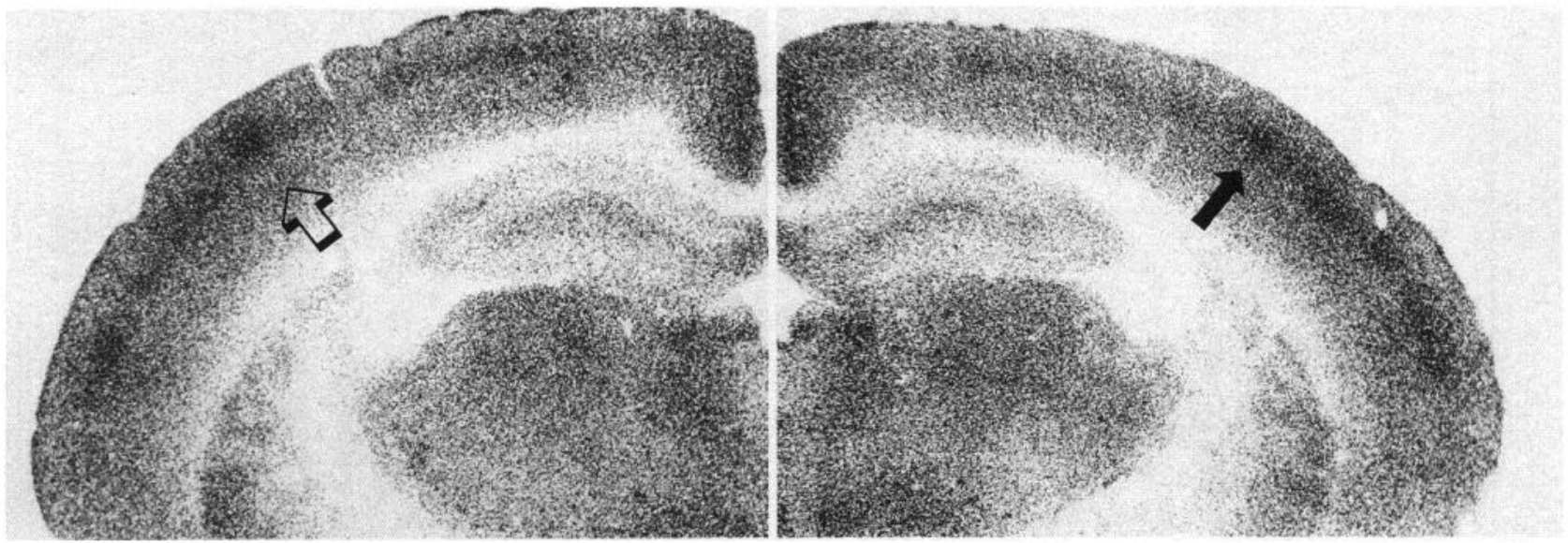

Figure 7. 2-DG autoradiograph (photographed directly from the film) from a rat that received a unilateral basal forebrain lesion and bilateral stimulation of the $\mathrm{C} 3$ whiskers. The solid arrow points to barrel-associated activity in the hemisphere ipsilateral to the lesion and is reduced in dimension compared to activity evoked in the contralateral hemisphere (open arrow).

(Fig. 8). The area of evoked uptake was similar between the hemispheres of rats that received sham lesions of the basal forebrain (Fig. 9).

By expressing the size of the activated barrel in the experimental hemisphere as a percentage of the corresponding barrel in the normal hemisphere, we calculated the percentage size difference of activated barrels between hemispheres (sham, $N$ $=3$; excitotoxic, $N=4$ ). Figure 10 demonstrates that the percentage areal difference for matched sites in the two hemispheres is greater for excitotoxic-lesioned animals. In addition, when the relationship between the dimension of the evoked activity and amount of AChE innervation is plotted, a significant cor-
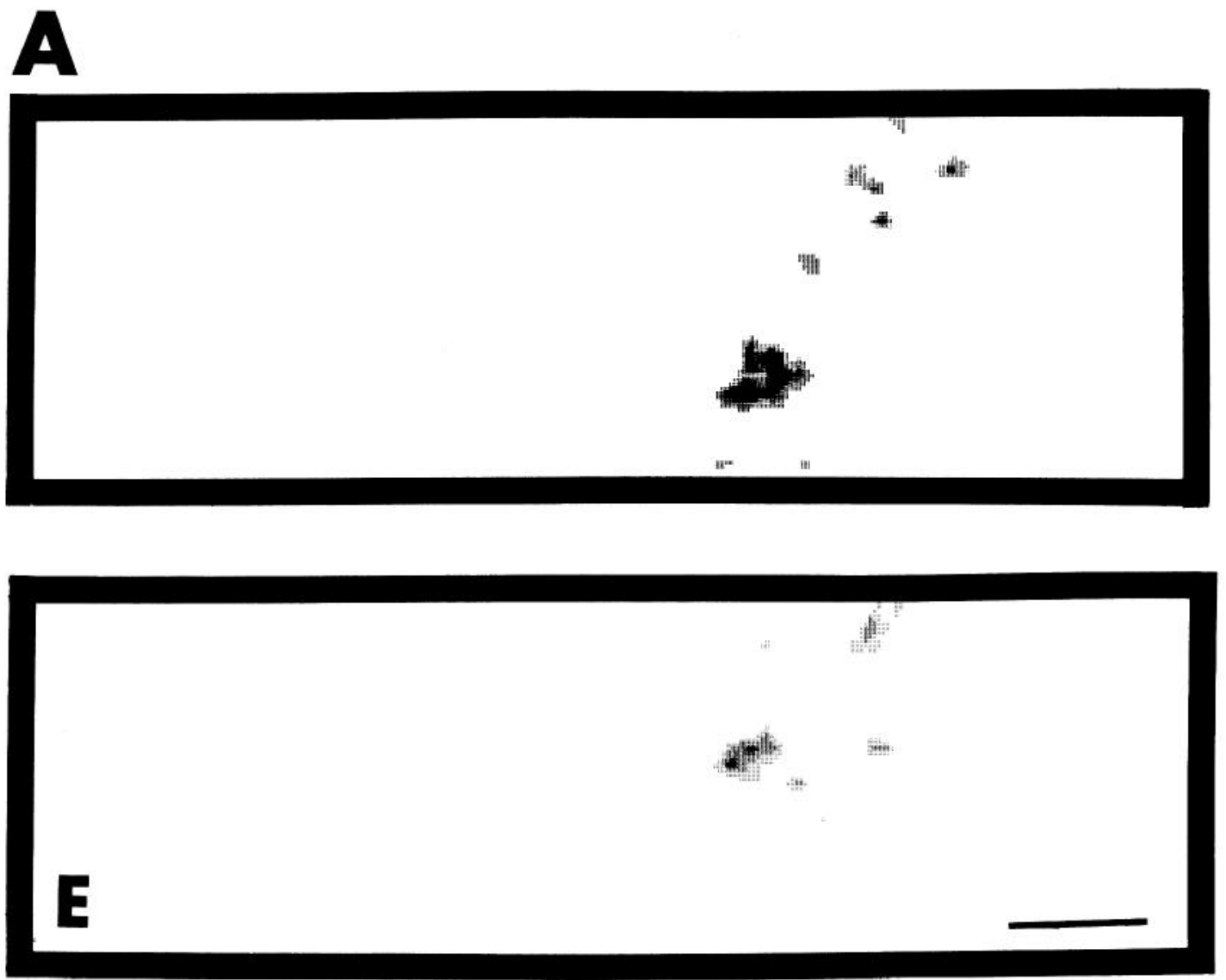

Figure 8. $A$ and $B$, Digitized maps of stimulus-evoked metabolic uptake through the barrel cortex of two rats that received behavioral training on a tactile discrimination task and a unilateral excitotoxic lesion of the basal forebrain $(E)$. The experimental hemispheres $($ below) reveal reduced barrel-like spots of activity compared with activity evoked in the corresponding barrels in the contralateral normal hemispheres (above). The spots 
relation emerges between the two variables (Fig. 11). Therefore, the less $\mathrm{AChE}$ present in the cortex, the smaller the patch of 2-DG uptake and vice-versa.

\section{Discussion}

We examined the behavioral consequence of cortical ACh depletion after basal forebrain lesions. The performance of AChdepleted rats on a previously learned task of processing sensory information with their whiskers was initially impaired, but after 2-8 weeks of postlesion testing, returned to prelesion levels of ability. Sham-lesioned rats experienced no such postlesion disruption of task performance. The time it took an animal to return to prelesion levels of sensory discrimination was positively correlated with the extent of AChE depletion. The impairment on this specific task was transient, however, since the ACh-depleted animals eventually returned to prelesion performance levels. Our findings suggest that basal forebrain lesions, which disrupt cholinergic innervation to the somatosensory cortex, interfere with the animal's ability to process sensory information passively applied to the whiskers.

Despite this behavioral recovery, the areal spread of 2-DG uptake in response to whisker stimulation in the ACh-depleted hemispheres was reduced compared to the activity evoked in the opposite, unlesioned hemispheres. No differences in 2-DG uptake were observed between hemispheres of sham-lesioned animals. This pattern of reduced metabolic uptake is similar to findings in animals that received unilateral basal forebrain lesions of shorter duration without participating in behavioral testing (Ma et al., 1989; Jacobs et al., 1991).

\section{Appetitive rewards and cortical ACh release}

Electrophysiological studies indicate that discharge rates of basal forebrain neurons increase transiently during the acquisition of learned behaviors that are closely tied to a food reward (Richardson and DeLong, 1990). Not only do basal forebrain neurons respond to the food reward itself, but they are also activated by stimuli that consistently precede the reward delivery (Richardson and DeLong, 1986). In addition, stimulation of the basal forebrain results in increased release of $\mathrm{ACh}$ in the cerebral cortex, including somatosensory cortex (Rasmusson et al., 1992). Furthermore, presenting an appropriate sensory stimulus in the presence of $\mathrm{ACh}$ increases the strength of the neuronal response to the sensory input (e.g., Sillito and Kemp, 1983; Donoghue and Carroll, 1987; Metherate et al., 1987). Since association of a stimulus with a food reward activates the basal forebrain, under normal conditions, this would optimize the cortical response to an appetitively tied sensory stimulus. In our task, an animal's correct response to the stimulus was rewarded with a food pellet. Even though the sensory processing was initially deficient, perhaps in the presence of a food reward remaining
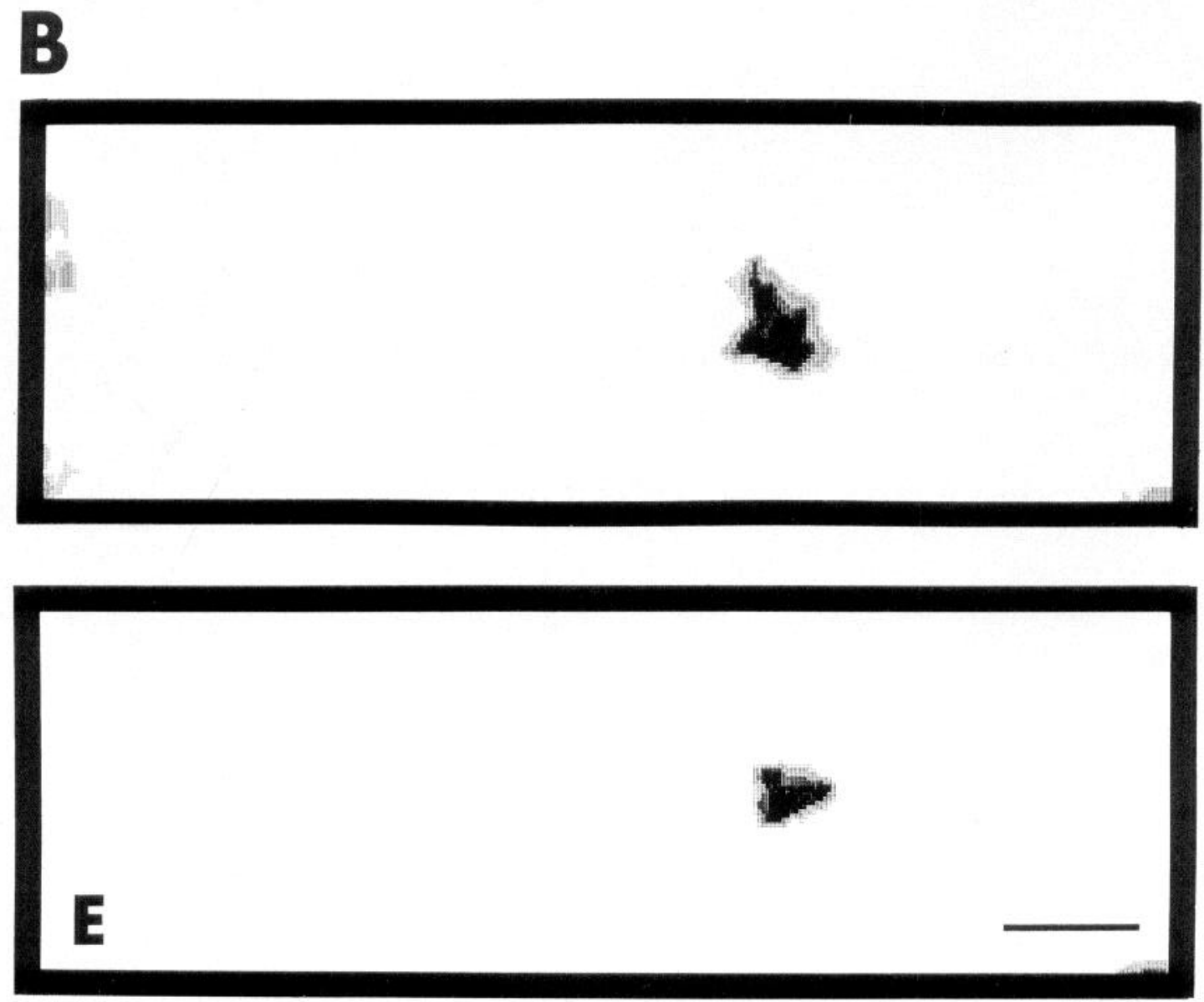

of label are $2 \mathrm{SD}$ or more above the mean for the entire distribution. The reduction in activated barrel size persists despite behavioral recovery. Scale $=1 \mathrm{~mm}$. 

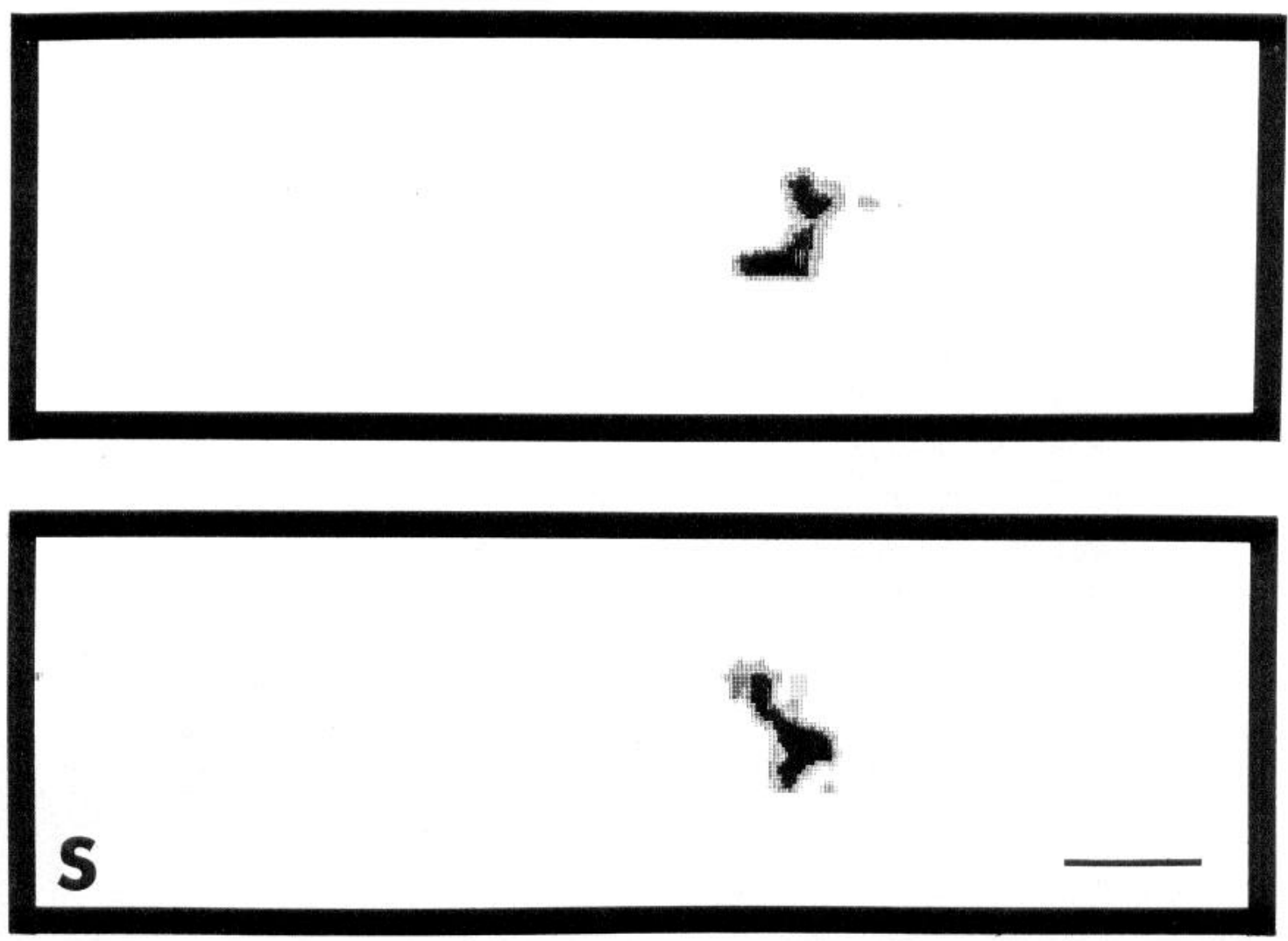

Figure 9. Digitized maps generated from a rat trained on the behavioral task of tactile discrimination that received a sham lesion of the basal forebrain $(S)$. The stimulus-evoked 2-DG activity associated with bilateral stimulation of the C3 whiskers in the experimental hemisphere (bottom map) is similar in size to that evoked in the normal hemisphere (top map). The spots of label correspond to activity 2 SD or more above the mean value for the entire map. Scale $=1 \mathrm{~mm}$.

basal forebrain cells were strongly activated and, ultimately, the rat could perform at prelesion levels of stimulus detection. During the 2-DG study, however, there was no association between the stimulus and food; therefore, increased activity of the remaining basal forebrain cells did not occur and the metabolic pattern remained reduced.

\section{Does cholinergic depletion impair sensory discrimination?}

Depletion of cortical ACh as a consequence of a basal forebrain lesion results in significantly impaired discrimination using other sensory modalities. Ridley et al. (1986) demonstrated disruption of the ability to visually discriminate between previously learned stimuli after bilateral basal forebrain lesions. In the same study, presentation of a new visual discrimination task during administration of a cholinergic agonist improved the performance of lesioned animals, which was later disrupted by administration of scopolamine, a cholinergic antagonist. Everitt et al. (1987) assessed the effects of bilateral basal forebrain lesions in rats pretrained on a conditional visual discrimination task. They found that sham-lesioned rats required many fewer retraining sessions to reachieve prelesion performance than the lesioned group, similar to observations of this study. Additionally, Everitt et al. (1987) observed the greatest amount of ChAT depletion associated with the most severe behavioral impairment. The design of both these studies is similar to the one reported here, in that they test postlesion retention of a sensory discrimination (in their case, visual), but bilateral basal forebrain lesions were made (as opposed to our unilateral). The authors of both sets of experiments interpret their findings in the context of impaired learning, although Ridley et al. (1986) suggest that the ability to perform may depend on cortical neurons maintaining a minimum level of activity. In contrast, Wozniak et al. (1989b), using a slightly different experimental design (testing acquisition of a task after basal forebrain lesions) demonstrated tactile discrimination deficits in rats, and suggested the impairment was attributable to altered processing of information in the somatosensory cortex due to the absence of cholinergic innervation. In any case, when assessing performance of pretrained animals on tasks of sensory information processing, studies relating the degree of cholinergic depletion (ChAT and/or AChE) to resulting behavioral deficits agree that animals with greater depletion require a longer time to return to criterion. It is difficult in any single study to clearly distinguish between the components of "learning" versus the components of sensory processing. Sensory processing may be a graded phenomenon in terms of the amount of cholinergic depletion, consistent with the contribution ACh makes in improving the 'signal-to-noise' ratio of neuronal activity (McCormick and Prince, 1986). Such observations are supported by the findings of this study, which indicate that rats with greater AChE depletion displayed both impaired performance and reduced 2-DG uptake. More recent research suggests that the consequence of $\mathrm{ACh}$ on cerebral cortex may be more properly interpretcd as affecting attention (see below). This theory also conforms to the results described here and the notion that $\mathrm{ACh}$ increases the signal-to-noise ratio of neuronal activity. 
Percent Decrease in Area of 2-DG Label

Evoked in Experimental Hemisphere as

Compared to its Contralateral Counterpart

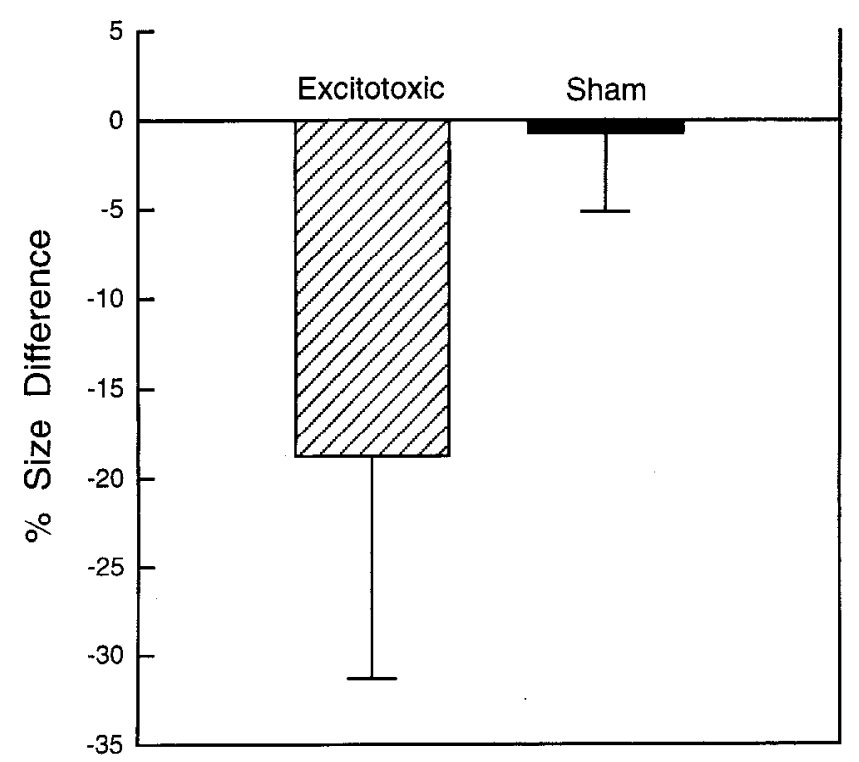

Figure 10. The dimension of the activated barrels in experimental hemispheres of three sham-lesioned and four excitotoxic-lesioned rats was expressed as a percentage of the corresponding matched barrels in the contralateral normal hemisphere. The percentage size difference between hemispheres is substantially greater in the excitotoxic-lesioned group.

\section{Is barrel cortex necessary for stimulus detection?}

A number of researchers have demonstrated that barrel cortex is required to perform sensory discriminations such as roughsmooth or frequency detection distinctions (Simons et al., 1975; Guic-Robles et al., 1989; Carvell and Simons, 1990). Hutson and Masterton (1986), however, found that simple detection of tactile stimulation to the whiskers does not require barrel cortex; they suggest that simple detection may be performed at a subcortical level. In our study, rats were initially impaired in tactile detection after ACh depletion, although over a period of several ${ }^{*}$ weeks they recovered. The study by Hutson and Masterton (1986) does not provide a timc frame, so it is difficult to compare our study to theirs in this regard. The fact that both sets of rats could perform a detection task does not necessarily mean that similar mechanisms were used to perform the detection. For example, the stimulus used in the experiments was different (air puff vs. probe). In addition, the rats in our study possessed an intact barrel cortex (without proper ACh innervation), whereas in the Hutson and Masterton study, the barrel cortex was removed. A different experiment that served as a model for the stimulus paradigm used in our study suggests that barrel cortex is required for detection of passively applied stimuli. Hurwitz et al. (1990) found that rats with unilateral thrombotic infarctions of the barrel field never fully achieved preinfarct levels of ability to detect the stimulus, although the infarcted rats improved over time.

We suggest that the lack of ACh interfered with the ability of excitotoxic-lesioned animals to process stimuli at full capacity. The rats in our study were initially impaired in the detection task even though they had an intact barrel cortex. We cannot prove that they used barrel cortex neurons to perform the sen-

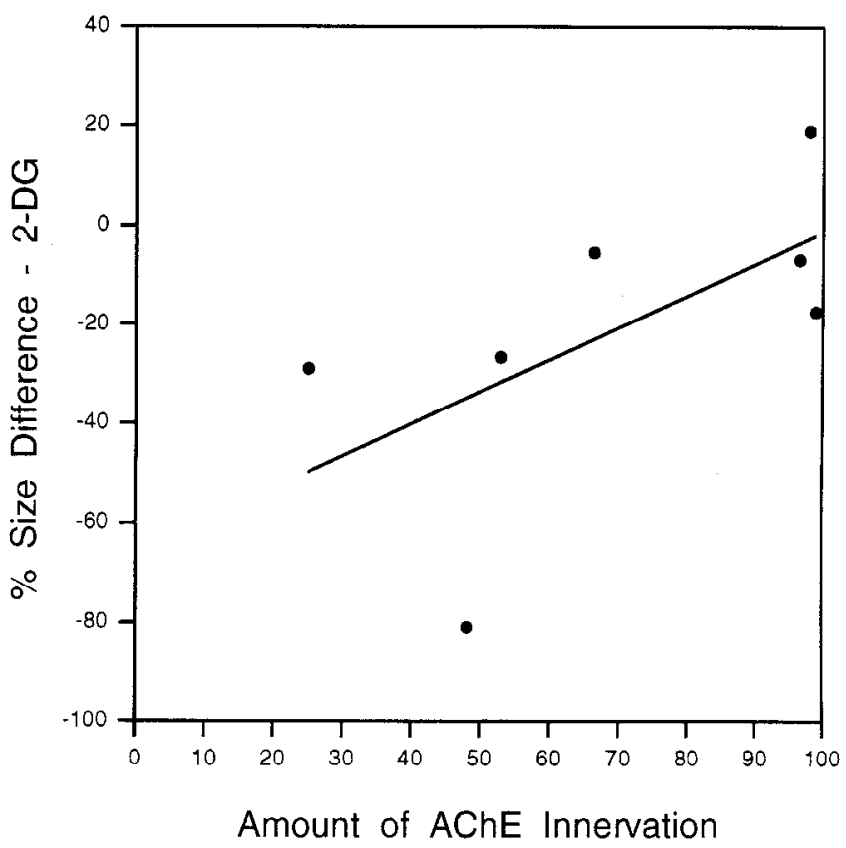

Figure 11. A scatterplot of the relationship between the amount of cortical AChE in the experimental hemispheres (expressed on the abscissa as the percentage of AChE staining in the opposite normal hemisphere) and the size of the stimulus-evoked spots of 2-DG label in the same regions. The dimension of the label is expressed on the ordinate as the percentage difference between matched sites in each hemisphere. The percentage areal difference in the experimental hemispheres of three sham-lesioned and four excitotoxic-lesioned rats is significantly negatively correlated with the amount of cortical AChE depletion in these same hemispheres $(p<0.05)$.

sory discrimination, but the observation that the appropriate barrels take up significant amounts of 2DG when whiskers are passively stimulated suggests that barrel neurons respond during both passive and active stimulation. Whatever compensations were applied by the rats, the paradigm we used was, indeed, a relatively simple task of sensory discrimination. Since ACh has been shown to enhance cortical neural activity when combined with an appropriate stimulus, performance in a more demanding task might have required continued enhancement of neural activity that $\mathrm{ACh}$ provides. In this regard, a more complex task involving active discrimination with the whiskers may reflect more enduring behavioral deficits as a consequence of cortical ACh depletion.

\section{Arousal and the basal forebrain}

Recent studies in which the basal forebrain was either stimulated or damaged by excitotoxic lesions indicate a corresponding increase or decrease in cortical ACh release and EEG activation patterns associated with arousal (Stewart et al., 1984). These findings bolster the current notion that the cholinergic basal forebrain-neocortical pathway is a major route leading to cortical activation (Détári and Vanderwolf, 1987; Steriade and Buzsáki, 1990; Metherate et al., 1992). If the basal forebrain does mediate the state of cortical activation, as reflected in the EEG, then damage to these cells might impair ability to attend during sensory stimulation. It is possible that the disruption we noted in tactile discrimination performance of the basal forebrainlesioned rats was the result of impaired attentional processes. Dunnett et al. (1991) reviewed the behavioral effects of similar lesions and suggested that the basal forebrain cholinergic system 
played a role in selective attention, an interpretation they viewed as consistent with its role in arousal. Subsequent studies in rats and monkeys with either lesions or infusions of GABAergic agonists into the basal forebrain add support to the idea that cholinergic disruption has more consistent adverse effects on attention than learning and memory (Muir et al., 1993; Pang et al., 1993; Wenk, 1993; Voytko et al., 1994). As indicated above, the notion that $\mathrm{ACh}$ depletion plays a role in mechanisms of attention is consistent with its effect on increasing the signalto-noise response.

The fact that the animals were pretrained on the task may have served as a basis for the overall improvement in performance. The responsiveness of specific cells may have been "conditioned" during the training period, and since this was not a task of new learning, the conditioning allowed the animal to ultimately perform the task regardless of the reduced cortical activity reflected in the $2-\mathrm{DG}$ data. Another interpretation that also considers the 2-DG profiles of the ACh-depleted animals, is that loss of basal forebrain neurons and reduction in arousal, typically reflected by a more synchronized EEG, may render a previously adequate sensory stimulus no longer sufficient for the cortical neuron to reach threshold and also lower the ability of a cell to maintain neuronal responses. As a result, a given cell is less able to activate adjacent neurons. The animals may have compensated behaviorally, perhaps by more efficient use of remaining basal forebrain neurons, but functional cortical activity, as assessed by the 2 -DG technique, continued to demonstrate reduced responsiveness.

$\mathrm{ACh}$ is an important factor in cortical sensory processing (Krnjevic et al., 1971; Brown, 1983; McCormick and Prince, 1985). While memory-related interpretations are frequently applied to explain basal forebrain lesion results, the findings from this study support and expand the view that ACh is an integral component in executing a learned response to a sensory discrimination task.

\section{References}

Bartus RT, Dean RL, Beer B, Lippa AS (1982) The cholinergic hypothesis of geriatric memory dysfunction. Science 217:408-417.

Bear MF, Singer W (1986) Modulation of visual cortical plasticity by acetylcholine and noradrenaline. Nature 320:172-176.

Brown DA (1983) Slow cholinergic excitation-a mechanism for increasing neuronal excitability. Trends Neurosci 6:302-307.

Candy J, Perry R, Perry E, Irving D, Blessed G, Fairbairn A, Tomlinson $B$ (1983) Pathological changes in the nucleus of Meynert in Alzheimer's and Parkinson's disease. J Neurol Sci 54:277-289.

Carvell GE, Simons DJ (1990) Biometric analyses of vibrissal tactile discrimination in the rat. J Neurosci 10:2638-2648.

Collerton D (1986) Cholinergic function and intellectual decline in Alzheimer's disease. Neuroscience 19:1-28.

Coyle JT, Price DL, DeLong MR (1983) Alzheimer's disease: a disorder of cortical cholinergic innervation. Science 219:1184-1190.

Détári L, Vanderwolf $\mathrm{CH}$ (1987) Activity of identified cortically projecting and other basal forebrain neurones during large slow waves and cortical activation in anaesthetized rats. Brain Res 437:1-8

Donoghue JP, Carroll KL (1987) Cholinergic modulation of sensory responses in rat primary somatic sensory cortex. Brain Res 408:367371.

Dunnett, SB, Everitt, BJ, Robbins, TW (1991) The basal forebraincortical cholinergic system: interpreting the functional consequences of excitotoxic lesions. Trends Neurosci 14:494-501.

Everitt BJ, Robbins TW, Evenden JL, Marston HM, Jones GH, Sirkia TE (1987) The effects of excitotoxic lesions of the substantia innominata, ventral and dorsal globus pallidus on the acquisition and retention of a conditional visual discrimination: implications for cholinergic hypotheses of learning and memory. Neuroscience 22:441469.
Freedman M, Oscar-Berman M (1987) Tactile discrimination learning deficits in Alzheimer's and Parkinson's diseases. Arch Neurol 44:394398.

Guic-Robles E, Valdivieso C, Guajardo G (1989) Rats can learn a roughness discrimination using only their vibrissal system. Behav Brain Res 31:285-289.

Guic-Robles E, Jenkins WM, Bravo H (1992) Vihrissal roughness discrimination is barrelcortex-dependent. Behav Brain Res 48:145152.

Höhmann CF, Brooks AR, Coyle JT (1988) Neonatal lesions of the basal forebrain cholinergic neurons result in abnormal cortical development. Dev Brain Res 42:253-264.

Hurwitz BE, Dietrich WD, McCabe PM, Watson BD, Ginsberg MD, Schneiderman N (1990) Sensory-motor deficit and recovery from thrombotic infarction of the vibrissal barrel-field cortex. Brain Res 512:210-220.

Hutson KA, Masterton RB (1986) The sensory contribution of a single vibrissa's cortical barrel. J Neurophysiol 56:1196-1223.

Irle E, Markowitsch HJ (1987) Basal forebrain-lesioned monkeys are severely impaired in tasks of association and recognition memory. Ann Neurol 22:735-743.

Jacobowitz DM, Creed GJ (1983) Cholinergic projection sites of the nucleus of tractus diagonalis. Brain Res Bull 10:365-371.

Jacobs SE, Code RA, Juliano SL (1991) Basal forebrain lesions alter stimulus-evoked metabolic activity in rat somatosensory cortex. Brain Res 560:342-345.

Johnston MV, McKinney M, Coyle JT (1979) Evidence for a cholinergic projection to neocortex from neurons in basal forebrain. Proc Natl Acad Sci USA 76:5392-5396.

Juliano SL, Ma W, Bear MF, Eslin D (1990) Cholinergic manipulation alters stimulus-evoked activity in cat somatosensory cortex. J Comp Neurol 297:106-120.

Juliano SL, Ma W, Eslin D (1991) Cholinergic depletion prevents expansion of topographic maps in somatosensory cortex. Proc Natl Acad Sci USA 88:780-784.

Koelle GB (1955) The histochemical identification of acetylcholinesterase in cholinergic, adrenergic and sensory neurons. J Pharmacol Exp Ther 114:167-184.

Krnjevic K, Pumain R, Renaud L (1971) The mechanism of excitation by acetylcholine in the cerebral cortex. J Physiol (Lond) 215:247268.

Lamour Y, Dutar P, Jobert A, Dykes RW (1988) An iontophoretic study of single somatosensory neurons in rat granular cortex serving the limbs: a laminar analysis of glutamate and acetylcholine effects on receptive-field properties. J Neurophysiol 60:725-750.

Ma W, Höhmann CF, Coyle JT, Juliano SL (1989) Lesions of the basal forebrain alter stimulus-evoked metabolic activity in mouse somatosensory cortex. J Comp Neurol 288:414-427.

McCormick DA (1990) Cellular mechanisms of cholinergic control of neocortical and thalamic neuronal excitability. In: Brain cholinergic systems (Steriade M, Biesold D, eds), pp 236-264. New York: Oxford UP.

McCormick DA, Prince DA (1985) Two types of muscarinic response to acetylcholine in mammalian cortical neurons. Proc Natl Acad Sci USA 82:6344-6348.

McCormick DA, Prince DA (1986) Mechanisms of action of acetylcholine in the guinea-pig cerebral cortex in vitro. J Physiol (Lond) 375:169-194.

McKenna TM, Ashe JH, Hui GK, Weinberger NM (1988) Muscarinic agonists modulate spontaneous and evoked unit discharge in auditory cortex of cat. Synapse 2:54-68.

Mesulam M-M, Mufson EJ, Wainer BH, Levey AI (1983) Central cholinergic pathways in the rat: an overview based on an alternative nomenclature (Ch1-Ch6). Neuroscience 10:1185-1201.

Metherate R, Weinberger NM (1989) Acetylcholine produces stimulus-specific receptive field alterations in cat auditory cortex. Brain Res 480:372-377.

Metherate R, Weinberger NM (1990) Cholinergic modulation of responses to single tones produces tone-specific receptive field alterations in cat auditory cortex. Synapse 6:133-145.

Metherate R, Tremblay N, Dykes RW (1987) Acetylcholine permits long-term enhancement of neuronal responsiveness in cat primary somatosensory cortex. Neuroscience 22:75-81.

Metherate R, Tremblay N, Dykes RW (1988a) The effects of acetyl- 
choline on response properties of cat somatosensory cortical neurons. J Neurophysiol 59:1231-1252.

Metherate R, Tremblay N, Dykes RW (1988b) Transient and prolonged effects of acetylcholine on responsiveness of cat somatosensory cortical neurons. J Neurophysiol 59:1253-1276.

Metherate R, Cox CL, Ashe JH (1992) Cellular bases of neocortical activation: modulation of neural oscillations by the nucleus basalis and endogenous acetylcholine. J Neurosci 12:4701-4711.

Muir JL, Page KJ, Sirinathsinghji DJS, Robbins TW (1993) Excitotoxic lesions of basal forebrain cholinergic neurons: effects on learning, memory, and attention. Behav Brain Res 57:123-131.

Nissen MJ, Corkin S, Buonanno FS, Growdon JH, Wray SH, Bauer J (1985) Spatial vision in Alzheimer's disease. Arch Neurol 42:667671.

Pang K, Williams MJ, Egeth H, Olton DS (1993) Nucleus basalis magnocellularis and attention: effects of muscimol infusions. Behav Neurosci 107:1031-1038.

Paxinos G, Watson C (1982) The rat brain in stereotaxic coordinates. New York: Academic.

Price DL, Whitehouse PJ, Strubble RG, Coyle JT, Clark AW, DeLong MR, Cork LC, Hedreen JC (1982) Alzheimer's disease and Down's syndrome. Ann NY Acad Sci 396:145-164.

Rasmusson DD, Chow K, Szerb JC (1992) Frequency-dependent increase in cortical acetylcholine release evoked by stimulation of the nucleus basalis magnocellularis in the rat. Brain Res 595:150-154.

Richardson RT, DeLong MR (1986) Nucleus basalis of Meynert neuronal activity during a delayed response task in monkey. Brain Res 399:364-368.

Richardson RT, DeLong MR (1990) Responses of primate nucleus basalis to water rewards and related stimuli. In: Brain cholinergic systems (Steriade M, Biesold D, eds), pp 282-293. New York: Oxford UP.

Ridley RM, Baker HF, Drewett B, Johnson JA (1985) Effects of ibotenic acid lesions of the basal forebrain on serial reversal learning in marmosets. Psychopharmacology (Berl) 86:4380-443.

Ridley RM, Murray TK, Johnson JA, Baker HF (1986) Learning impairment following lesion of the basal nucleus of Meynert in the marmoset: modification by cholinergic drugs. Brain Res 376:108116.

Saper CB (1984) Organization of cerebral cortical afferent system in the rat. I. Magnocellular basal nucleus. J Comp Neurol 222:313-342.

Sato $H$, Hata Y, Masui $H$, Tsumoto $T$ (1987) A functional role of cholinergic innervation to neurons in the cat visual cortex. J Neurophysiol 58:765-780.
Sillito AM, Kemp JA (1983) Cholinergic modulation of the functional organization of the cat visual cortex. Brain Res 289:143-155.

Simons D, Puretz J, Finger S (1975) Effects of serial lesions of somatosensory cortex and further neodecortication on tactile retention in rats. Exp Brain Res 23:353-365.

Steriade M, Buzsáki G (1990) Parallel activation of thalamic and cortical neurons by brainstem and basal forebrain cholinergic systems. In: Brain cholinergic systems (Steriade M, Biesold D, eds), pp 3-62. New York: Oxford UP.

Stewart DJ, MacFabe DF, Vanderwolf CH (1984) Cholinergic activation of the electrocorticogram: role of substantia innominata and effects of atropine and quinuclidinyl benzylate. Brain Res 322:219232.

Stichel CC, Singer W (1987) Quantitative analysis of the choline acetyltransferase-immunoreactive axonal network in the cat primary visual cortex: I. Adult cats. J Comp Neurol 258:91-98.

Tommerdahl M, Baker R, Whitsel BL, Juliano SL (1985) A method for reconstructing patterns of somatosensory cerebral cortical activity. Biomed Sci Instrum 21:93-98.

Voytko ML, Olton DS, Richardson RT, Gorman LK, Tobin JR, Price DL (1994) Basal forebrain lesions in monkeys disrupt attention but not learning and memory. J Neurosci 14:167-186.

Webster HH, Hanisch U-K, Dykes RW, Biesold D (1991) Basal forebrain lesions with or without reserpine injection inhibit cortical reorganization in rat hindpaw primary somatosensory cortex following sciatic nerve section. Somatosens Motor Res 8:327-346.

Wenk GL (1993) A primate model of Alzheimer's disease. Behav Brain Res 57:117-122.

Whitehouse PJ, Price DL, Clark AW, Coyle JT, DeLong MR (1981) Alzheimer disease: evidence for selective loss of cholinergic neurons in the nucleus basalis. Ann Neurol 10:122-126.

Whitehouse PJ, Price DL, Strubble RG, Clark AW, Coyle JT, DeLong MR (1982) Alzhcimcr's discase and scnilc dementia: loss of neurons in the basal forebrain. Science 215:1237-1239.

Wong-Riley M (1979) Changes in the visual system of monocularly sutured or enucleated cats demonstrable with cytochrome oxidase histochemistry. Brain Res 171:11-28.

Wozniak DF, Stewart GR, Finger S, Olney JW (1989a) Comparison of behavioral effects of nucleus basalis magnocellularis lesions and somatosensory cortex ablation in the rat. Neuroscience 32:685-700.

Wozniak DF, Stewart GR, Finger S, Olney JW, Cozzari C (1989b) Basal forebrain lesions impair tactile discrimination and working memory. Neurobiol Aging 10:173-179. 